\title{
COMPENSAÇÃO AMBIENTAL: LEI COMPLEMENTAR \\ MUNICIPAL 757 DE PORTO ALEGRE, RS, BRASIL
}

\author{
VLADIMIR STOLZENBERG TORRES \\ Biólogo e Gestor Ambiental \\ Ms. em Biociências, Dr. em Informática na Educação \\ Secretaria Municipal do Meio Ambiente de Porto Alegre, RS \\ biologo.vladimir@gmail.com
}

RESUMO: A questão ambiental é, sem dúvida, o "fato do momento" na civilização humana contemporânea e, provavelmente, o de maior potencial de questionamento e transformação na trajetória do processo civilizatório. O estabelecimento e a expansão das urbes, acopladas a sua constante mutabilidade gerou a necessidade de minimizar os impactos ambientais ocasionados, através de medidas legislativas. Recentemente (janeiro de 2015) o Município de Porto Alegre editou a Lei Complementar $\mathrm{N}^{\circ} 757$ estabelecendo regras para a supressão, o transplante ou a poda de espécimes vegetais. A lei, entretanto, apoia-se em conceitos clássicos e ortodoxos para arbitrar o manejo, deixando de considerar o ambiente como algo sistêmico, com amplas interações, particularmente com a fauna.

Palavras-chave: Direito ambiental, legislação, compensação, meio ambiente.

ABSTRACT: The environmental question is the moment topic of contemporary human civilization and, probably, that with the greatest potential for questioning and transformation in the trajectory of the civilizing process. The establishment and expansion of cities, coupled with its constant mutability generated the need to minimize environmental impacts caused by legislative measures. Recently (January 2015) the city of Porto Alegre edited Complementary Law No. 757 establishing rules for the removal, transplantation or pruning of plant specimens. The law, however, is based on classical and orthodox concepts to arbitrate management, failing to consider the environment as something systemic, with extensive interactions, particularly with wildlife.

Keywords: Environmental law, legislation, compensation, environment. 


\section{INTRODUÇÃO}

Conforme Torres (2014), a questão ambiental está sempre vinculada a um contexto histórico social específico. Em dado período histórico, a relação entre a sociedade humana e os recursos naturais dos quais supriam suas necessidades básicas depende de fatores relacionados às técnicas de exploração desses recursos e da organização do trabalho. Atualmente, o problema ambiental enquanto problema real da sociedade humana reflete não só o estágio de desenvolvimento das técnicas para o domínio da natureza e para produção da vida material, mas também as relações sociais de produção, a relação do homem com os recursos naturais que dispõem e, acima de tudo, a sua relação com suas próprias necessidades objetivas e subjetivas.

Além disto, é fato amplamente conhecido que a vida, a saúde e o bem-estar físico e psíquico do ser humano depende, em grande parte, das boas condições do ambiente, ou seja, do permanente equilíbrio ambiental. Tanto isto é verdade que a Constituição Federal afirma, que o meio ambiente ecologicamente equilibrado é essencial à sadia qualidade de vida, o que faz a doutrina afirmar que a proteção do meio ambiente é a proteção da própria dignidade humana (FIORILLO, 2004, p. 56).

A satisfação das necessidades e das aspirações sociais é a finalidade primordial do desenvolvimento (AGRA-FILHO, 2008). Mas como não se pode abrir mão nem do desenvolvimento econômico nem da proteção ambiental - sem eles padecer-se-ia - certo é o comando que determina uma harmonização entre ambos, harmonização esta que colocará rédeas no desenvolvimento econômico, sem contudo proibi-lo ou estagná-lo, e que tolerará algumas mudanças negativas no status quo ambiental, sem, contudo, permitir riscos graves e modificações desproporcionais e insuportáveis.

Porém, as paisagens urbanas, o extremo da variação da influência humana na dinâmica de ecossistemas (FORMAN e GORDON, 1986, p. 3), se expandiram de forma dramática recentemente, particularmente nos países em desenvolvimento (COHEN, 2004). Nos últimos 40 anos, a população mundial aumentou em 65\%, enquanto a população urbana aumentou em 115\% (Organização das Nações Unidas, 2003). Durante o mesmo período, a população brasileira aumentou em $82 \%$, e sua fração urbana em 165\% (IBGE, 2000, p. 88).

A conservação da biodiversidade em ambientes urbanos é um desafio. Áreas verdes oferecem hábitats e recursos para a biodiversidade,

mas o crescimento urbano também apresenta ameaças. Enquanto aumenta a complexidade das áreas urbanas, incluindo novas combinações de uma ampla e refinada mistura de biótopos (YLIPELKONEN e NIEMELÄ, 2005; ZIPPERER et al., 2000; WINTLE et al., 2005), os subúrbios em crescimento os rearranjam em um padrão desintegrado, perturbam as trajetórias sucessionais nas áreas verdes remanescentes (REBELE, 1994; TREPL, 1995, p. 16), e favorecem o domínio por espécies exóticas (YLI-PELKONEN e NIEMELÄ, 2005). Enquanto os valores estéticos e serviços 
ecossistêmicos das áreas verdes são reconhecidos economicamente, afetando os valores de terras e propriedades (TYRVÄINEN, 1997; BREUSTE, 2004; LI, 2005), seu papel na proteção da biodiversidade raramente é reconhecido ou levado em consideração no planejamento urbano (BATTISTI e GIPPOLITI, 2004).

A relação da sociedade com a natureza e sua preservação apresenta-se, por conseguinte, sob uma forma específica, suscitando de problemas relacionados a esta condição, com os problemas reais resultantes das relações do modo atual de produção da vida material humana. Assim, o presente estudo objetivou realizar uma análise da nova lei municipal de compensação ambiental, com foco nas suas inter-relação para com o mundo real no qual foi inserida, no âmbito do município de Porto Alegre, RS.

\section{COMPENSAÇÃO AMBIENTAL E VEGETAL}

A compensação vegetal originou-se nas práticas que antecederam a incorporação dos princípios do Estado Socioambiental estabelecido na Constituição de 1988 e consiste no reconhecimento da necessidade de particulares e do Poder Público plantarem vegetais na medida em que são suprimidos de forma autorizada, em decorrência do processo de urbanização e crescimento das cidades. Não se trata da compensação ambiental decorrente de atividades e empreendimentos sujeitos ao licenciamento ambiental que ganhou força no Brasil, a partir da lei do Sistema Nacional de Unidades de Conservação, mas que tem origem no direito brasileiro no art. $1^{\mathrm{o}}$ da Resolução Conama 10/87.

Assim, segundo Torres (2014), a compensação ambiental representa o instrumento utilizado para aqueles impactos que não são possíveis de serem mitigados, entre eles a perda da biodiversidade, a perda de áreas representativas do patrimônio cultural, histórico e arqueológico (WADA, s/d, p.i.). Trata-se de um mecanismo de indenização financeira à sociedade, como contrapartida a um dano causado ao meio ambiente.

Em 1988, a Constituição Federal incumbiu ao Poder Público "exigir, na forma da lei, para instalação de obra ou de atividade potencialmente causadora de significativa degradação do meio ambiente, estudo prévio de impacto ambiental, a que se dará publicidade" (Art. 225, § $1^{\circ}, \mathrm{IV}$ ).

Mesmo que a compensação não fosse prevista por mecanismos legais, ela é devida pelo princípio da responsabilidade objetiva ambiental (Art. $14, \S 1^{\circ}$, da Lei 6.938/81). Assim, em questões relacionadas com o ambiente, a expressão "compensação" é utilizada, em geral, em dois sentidos (FARIA, 2008, p. 36). Em sentido amplo, significa uma forma de reparação que compreende a recuperação de um ambiente alterado por uma atividade ou empreendimento, sem prejuízo de outras medidas adotadas - de natureza pecuniária ou não. Contudo, quando se realiza a referência a 
“medidas compensatórias", passa-se a conferir um sentido estrito à expressão. Nesse caso, estar-seia realizando referência a medidas de cunho não necessariamente pecuniário.

As medidas compensatórias, portanto, são aquelas destinadas a compensar impactos ambientais negativos, tomadas voluntariamente pelos responsáveis por esses impactos - ou exigidas pelo órgão ambiental competente (FARIA, 2008, p. 28). Destinam-se a compensar impactos irreversíveis e inevitáveis. Distinguem-se das denominadas “medidas mitigadoras”, destinadas a prevenir impactos adversos ou a reduzir aqueles que não podem ser evitados.

Fica evidente, portanto, que o termo compensação é utilizado, no Direito Ambiental, para veicular diferentes formas de se contrabalançar uma perda ambiental. O Código Florestal fala, por exemplo, em medidas compensatórias impostas ao interessado em suprimir vegetação de Áreas de Preservação Permanente ( $\operatorname{art} .4^{\circ}, \S 4^{\circ}$ ), ao mesmo tempo em que trata da compensação de Reserva Legal (art. 44); a Lei da Mata Atlântica estabelece compensação para supressão de vegetação deste bioma; a Lei do Sistema Nacional das Unidades de Conservação (Lei 9.985/2000) prevê a compensação ambiental antecipada, para fins de implantação de empreendimentos causadores de significativa degradação ambiental e a doutrina defende a compensação para os casos de danos ambientais irreversíveis, em que não seja possível a reparação in natura.

\section{SITUAÇÃO LEGAL DE PORTO ALEGRE}

No âmbito do município de Porto Alegre, por outro lado, sobressai-se a expressão "compensação vegetal", enquanto forma para compensar ambientalmente a eliminação de espécimes arbóreos. Assim visando à compensação vegetal, o primeiro Decreto de Porto Alegre que dispôs sobre a quantidade e a forma a ser compensada foi o de $n^{\circ} 8.186 / 83$. Posteriormente, vigorou o Decreto $n^{\circ}$ 10.380/92. Em 1996, foi editado o Decreto $n^{\circ} 11.476 / 96$, sendo revogado pelo Decreto $n^{\circ}$ $14.353 / 03$.

No ano de 2003, com a entrada em vigor do Decreto $n^{\circ} 14.353 / 03$, as intervenções em vegetais nesta cidade contavam com regras semelhantes às dispostas pelo Decreto $\mathrm{N}^{\mathbf{0}} 17.232$ de 2011. A quantidade de vegetais para reposição em caso de supressão, bem como a forma de conversão em caso de impossibilidade de reposição, foram tratadas utilizando-se, basicamente, os mesmos critérios, sendo que a última regra trouxe uma discreta elevação no que se refere aos padrões compensatórios.

Já, em 2006, houve o advento do Decreto n 15.418/06, reprisando regras do Estado e aumentando quantidades de vegetais a serem compensados por árvore suprimida. Contudo, paradoxalmente, mesmo aumentando a quantidade, a compensação é menos exigente, porque não compensa plantas exóticas, somente nativas, e o critério mínimo de altura adotado pelo Município é mais rigoroso. 
Assim, tanto na composição (não compensa exóticas), quanto na estrutura (tamanho, critério mínimo de altura) e na função (mudas em condições de plantio), o Decreto de 2006, representa menor rigor técnico e adequação à finalidade pretendida, que é o plantio e a manutenção das árvores no meio urbano.

O Decreto $n^{\circ} 17.232 / 11$ retomou critérios do Decreto $n^{\circ} 15.418 / 06$, que tecnicamente estariam adequados ao Plano de Arborização Urbana de Porto Alegre, datado de 2005, e que consolidou um padrão técnico para a compensação vegetal.

\section{LEI COMPLEMENTAR Nº 757, DE 14 DE JANEIRO DE 2015}

A LC 757 "estabelece regras para a supressão, o transplante ou a poda de espécimes vegetais no Município de Porto Alegre, revoga os Decretos $n^{\text {os }} 10.237$, de 11 de março de 1992, 10.258, de 3 de abril de 1992, 15.418, de 20 de dezembro de 2006, 17.232, de 26 de agosto de 2011, 18.083, de 21 de novembro de 2012, e 18.305, de 28 de maio de 2013, e dá outras providências".

Na justificativa do então Projeto de Lei encontra-se que:

"Este projeto de lei visa a atender ao disposto no parágrafo único do art. 243 da Lei Orgânica do Município de Porto Alegre, que determina que Lei Complementar definirá os casos em que, por risco à pessoa, dano ao patrimônio ou necessidade de obra pública ou privada, se admitirá o abate, poda ou o corte, e definirá sanções para os casos de transgressão ao disposto no "caput" e, ainda, atender ao que dispõe a Lei Complementar n. 65/81, estabelecendo um sistema de compensação vegetal, que até então vinha sendo regulado por meio de decretos, que seja harmônico com os princípios constitucionais".

Como se observa, já em sua origem, a LC 757 revela-se desconectada do conceito de floresta urbana, que será detalhado adiante, preocupando-se única e exclusivamente com as relações antrópicas que possam existir para com o verde urbano, deixando de considerar as inúmeras relações bióticas entre fauna e flora urbanas.

De acordo com a Constituição Federal de 1988, o Poder Público está incumbido de proteger a fauna e a flora, sendo que legalmente, todos os animais silvestres são de propriedade do Estado, portanto são vedadas as práticas que tragam algum tipo de risco à sua ecologia. A urbanização é um fator que interfere na vida destes animais, os quais são as principais vítimas. 


\section{A CONCEPÇÃO DE FLORESTA URBANA}

A disciplina jurídica das florestas no Brasil está inserida na Lei Federal No 12.651, de 25 de maio de 2012, recepcionada pela Constituição Federal de 1988 como norma geral. Aos demais entes federativos, nos termos da própria carta magna, cabe apenas suplementá-la (competência concorrente), sem contrariá-la. Entretanto, o referido diploma legal não define o termo floresta e tampouco outras normas o fazem, deixando ao intérprete da lei a árdua tarefa. Urge então uniformizar o conceito, vez que é utilizado amplamente nos mais variados textos legais, inclusive de natureza criminal.

Em não havendo definição em texto legal busca-se a interpretação mais adequada na literatura técnica vez que existe ramo próprio de ciência que trata do assunto, qual sejam, as ciências florestais, mais propriamente a engenharia florestal. Poderíamos buscar o entendimento gramatical da palavra mas é por demais simplista e pode levar a equívocos na administração da verdadeira justiça, fim colimado pelo ordenamento jurídico.

Se buscarmos uma interpretação histórica certamente a conclusão será outra pois no momento original da publicação da lei as florestas não naturais (exóticas) não abundavam em nosso meio, sendo tratadas como floresta apenas a mata densa e relativamente grande formada por árvores silvestres (nativas). Este entendimento não deve prevalecer, vigindo sim o entendimento atual de que existem vários tipos de florestas e, por não ter a lei restringido a aplicação do termo, não podemos fazê-lo.

A questão vai além, pois manejar floresta considerada de preservação permanente somente pode ser autorizada por órgão ambiental que detenha tal competência (relacionada com a escala de manejo), da mesma fora, a vegetação (aí natural ou não nos termos do código florestal) necessita de autorização órgão ambiental que emita a devida licença. Importa dizer então que o não entendimento correto do termo "floresta" pode significar em pedido de autorização para autoridade incompetente para deferi-lo, ocasionando vários traumas ao empreendedor de natureza administrativa, civil e criminal.

De acordo com a Organização das Nações Unidas para Alimentação e Agricultura (FAO), uma floresta se caracteriza como uma "área medindo mais de 0,5 ha com árvores maiores que 5m de altura e cobertura de copa superior a 10\%, ou árvores capazes de alcançar estes parâmetros in situ". Neste conceito não fica caracterizado o espaçamento entre espécimes, o que proporciona uma condição sui generis para a aplicação desta definição lato sensu ao contexto urbano.

O STJ e o TJ-MG, interessantemente, nos trazem o que não pode ser considerado como floresta; neste sentido, coleciona-se: 
"O elemento normativo 'floresta', constante do tipo de injusto do art. 38 da Lei 9.605/98, é a formação arbórea densa, de alto porte, que recobre área de terra mais ou menos extensa. O elemento central é o fato de ser constituída por árvores de grande porte. Dessa forma, não abarca a vegetação rasteira".(STJ, Resp 783652/SP, rel. Ministro Felix Fischer, DJU 19.06.20006, p. 196).

"APELAÇÃO CRIMINAL - CRIME AMBIENTAL - DESTRUIÇÃO DE VEGETAÇÃO RASTEIRA - DELITO NÃO CONFIGURADO - RECURSO PROVIDO. I - Para a configuração do crime do art. 38 da Lei $n^{\circ}$ 9.605/98 não basta que o agente intervenha em área de preservação permanente. O tipo penal exige destruição ou danificação de floresta (formada ou em formação). A supressão de vegetação rasteira, por não se incluir no conceito de floresta, não é suficiente para a caracterização do delito. II - Recurso provido". (Apelação Criminal no 1.0471.09.112014-0/001 - Rel.: Des. Eduardo Brum - Data Julg.: 12/12/2012 - Data Publ.: 19/12/2012). (Grifou-se).

Entendimento similar pode ser observado no TJ-RS, segundo o qual:

APELAÇÃO. CRIME AMBIENTAL. PESSOA JURÍDICA. CONCEITO DE FLORESTA. FAIXA DE DOMÍNIO DA REDE FERROVIÁRIA. IMPROVIMENTO $O$ art. 225, $\S 3^{o}$, da Constituição Federal e o art. $3^{\circ}$ da Lei 9605/98, não autorizam a responsabilização penal da pessoa jurídica por ato próprio, mas, tão-somente, por ato de seu representante legal, contratual ou de seu órgão colegiado. Vegetação esparsa, composta por arbustos e capoeiras, localizada na faixa de domínio da rede ferroviária e em área urbana, não pode ser considerada floresta, para efeitos de configuração de infração penal ambiental. Recurso improvido. (Apelação Crime No 70012991212, Quarta Câmara Criminal, Tribunal de Justiça do RS, Relator: Gaspar Marques Batista, Julgado em 20/10/2005)

O termo floresta urbana foi utilizado pela primeira vez em 1965, na América do Norte, como título de um estudo sobre os sucessos e os fracassos das plantações de árvores municipais numa zona da área metropolitana de Toronto (KONIJNENDIJK, 2003).

Conforme Torres et al. (prelo), no contexto brasileiro dois conceitos permeiam a gestão do verde urbano: arborização urbana e floresta urbana. O primeiro é o mais antigo e considerado como prevalente na cultura geral, enquanto o segundo tem encontrado óbices a sua utilização, principalmente em face dos gestores públicos. Além disto, existe uma confusão no uso do conceito de Floresta Urbana.

As fortes alterações que se verificam em meio urbano, suburbano e até rural, são motivadas pela atividade humana, sendo aquelas inquestionavelmente mais freqüentes nos centros urbanos onde, 
nomeadamente, levam à impermeabilização da superfície do solo, devido à construção de edifícios e à pavimentação de passeios, estradas e parques de estacionamento. Assim, diferentes associações de espécies florestais determinam as condições do ambiente para cada local. Caso o ambiente sofra modificações as associações vegetais também se modificam e adaptam-se às novas condições. De acordo com Schneider (1993, p. 228), esta alterações normalmente resultam em um empobrecimento da qualidade da floresta, o que não se confirma no contexto da floresta urbana, em face ao seu elevado equilíbrio dinâmico (PUENTE et al. 2005).

Para Marques-Neto e Viadana (2006) em áreas de adensamento urbano, onde se substituiu em quase sua totalidade a paisagem natural por uma construída e antropicamente modificada restando poucos locais favoráveis ao habitat da fauna local, e nos demais há considerável nível de degradação. Tal quadro denuncia o alto grau de ação antrópica no sistema, que enquanto contribui com a eliminação da diversidade, seleciona espécies que se destacam pela notória capacidade de adaptação.

Entre espécies de animais que incidem nas cidades existem os de interesse médico e de estudos epidemiológicos relativos á acidentes, revelando as principais espécies envolvidas e também fornecendo dados que podem ser utilizados em campanhas de prevenção subsidiando ações referentes á profilaxia e epidemiologia (CARVALHO e NOGUEIRA, 1998).

O estudo de Torres et al. (2015), no âmbito do Parque Municipal Chico Mendes revelou a presença em uma área com aproximadamente 25ha, de cinquenta e uma espécies de aves - sendo conhecida a ocorrência para os Parques de Porto Alegre, de número significativamente superior, neste sentido, considerando espécies migratórias e residentes (estas últimas oriundas de solturas indevidas, fugas de cativeiros ou mesmo uma migração de áreas periurbanas). O mesmo estudo demonstra a coexistência de espécies de mamíferos, tradicionalmente rotulados como domésticos, silvestres e sinantrópicos. A flora, ainda neste estudo, encontra-se representada por, pelo menos cinquenta e cinco espécies, convencionalmente divididas em exóticas e nativas!

A presença da avefauna brasileira em ambientes modificados pela ação antrópica, como as áreas urbanas, tem se tornado comum, já que, devido à diversificação do ambiente, tendem a sofrer variações menos acentuadas de recursos, mantendo sua diversidade de avefauna constante, o que explica a presença de $31 \%$ das aves brasileiras estarem representadas nestes ambientes (FRANCHIN et al., 2004).

Assim, o adensamento urbano leva à formação de inúmeros microecossistemas, os quais refletem diretamente na fauna urbana, o que a torna resultante de fatores tanto ecológicos como históricos e, portanto, não originada, somente, pela depauperação da composição faunística, original pelo processo de urbanização, mas, também, pela constante introdução de espécies (JAPYASSÚ e BRESCOVIT, 2006). 
A qualidade de um habitat pode ser avaliada pela presença ou ausência de determinadas espécies e por sua abundância, atuando como possíveis indicadores ambientais (FENTON et al. 1992, MEDELLÍN et al. 2000). A convivência "forçada", ocasionada pelas intervenções antrópicas no contexto das urbes, tem como consequência inevitável, a constituição de novas relações tróficas entre os componentes da biota que passam, então a coexistir.

Marti et al. (1993) apresentam resultados experimentais que contrariam as previsões da teoria de competição. A explicação alternativa levantada por estes autores cita o oportunismo no forrageamento como responsável pelos padrões encontrados por eles, e não a competição por presas, o que se aplica fundamentalmente ao observável em florestas urbanas e expressável através das figuras de números 1 a 3, nos quais se observam interações tróficas que não ocorreriam em condições naturais, em face da ausência do componente considerado como exótico.

Figura 1. Exemplar de Sanhaçu, Thraupis sayaca (Linnaeus, 1766), se alimentando em Escova-degarrafa, Callistemon aff. citrinus (Curtis) Skeels. (Myrtaceae) (Foto do autor). Neste caso, o espécime da avefauna seria considerado como nativo, enquanto a opção alimentar como de origem exótica.

Figura 2. Exemplar de Pardal, Passer domesticus (Linnaeus, 1758), se alimentando de brotos de Sibipiruna, Caesalpinia pluviosa DC. (Caesalpinioideae) (Foto do autor). Neste caso, o espécime vegetal seria considerado como nativo enquanto o espécime da avefauna, como exótico.

Figura 3. Enxame de Jataí, Tetragonisca angustula Latreille, 1811, alojado no interior de Cinamomo, Melia azedarach L. (Meliaceae) (Foto do autor). Mais uma interação possível, com um elemento exótico (cinamomo) proporcionando ambiente para estabelecimento de uma colméia de abelhas nativas, ampliando as opções de colmeação na floresta urbana.

\section{DISCUSSÃO E CONSIDERAÇÕES FINAIS}

Para Lima e Mendonça (2001) as cidades cada vez mais configuram um considerável desafio aos estudiosos do urbanismo e da natureza, visto que os problemas ambientais urbanos demandam a busca de soluções que ultrapassam o campo de disciplinas isoladas o que lhe confere o patamar de campo prático da interdisciplinaridade. 
Não resta então a menor dúvida que a definição de floresta, se não for suplementada por legislação específica nos termos da competência concorrente, deve ser atualmente interpretada como qualquer tipo de floresta, natural ou exótica, com uma ou mais espécies, e que quaisquer que sejam elas, cumprem a função socioambiental que se encaixa perfeitamente no texto constitucional e legal em vigor, qual seja: a proteção ambiental.

Assim ao se analisar a Lei Complementar $\mathrm{N}^{\circ} 757$, de 14 de janeiro de 2015, percebe-se que a mesma não define floresta, sem sequer se preocupa em definir outros termos que são apresentados na mesma; consequentemente demonstrando falta de preocupação do legislador para com a interpretação que possa ser dada a aspectos da mesma e, evidentemente demonstrando uma total desconexão para com a fauna urbana que esteja em usufruto da vegetação arbórea (principalmente, não se excluindo a rasteira), preocupando-se exclusivamente com o manejo do verde urbano lato sensu.

Neste sentido é conveniente suscitar o fato de que as urbes se constituem em meio ambientes artificiais, por conseguinte, não possuindo fauna ou flora autóctone stricto sensu, visto que todas foram objeto de introdução por influência antrópica.

Evidencia-se, por conseguinte, o estabelecimento de inúmeros nichos disponibilizados à ocupação por indivíduos que aportam às cidades de forma contínua. Criam-se, com isto, inúmeras relações bióticas e mesmo abióticas, diretas e indiretas em um continuum de transformações influenciadas pela atividade antrópica.

Esta "diversidade biológica" estabelecida no contexto urbano consegue compreender, de uma vez só, valor ecológico, genético, social, econômico, científico, educacional, cultural, recreativo e estético - bem como explica a CDB (Convenção Sobre Diversidade Biológica), assinada durante a Eco-Rio/92 e que tem como um de seus pilares a conservação da biodiversidade. O Brasil, como signatário da Convenção, comprometeu-se com todos os seus objetivos, devendo, pois, agir em prol da conservação da diversidade biológica.

Dentro deste cenário, Oliveira (1990) indica que o plano diretor de uma cidade deve levar em conta todas as vantagens que a arborização pública traz à população e à avefauna nativa, contemplando, em suas diretrizes políticas, metas que norteiem o gerenciamento sustentável das áreas verdes, onde a vegetação se caracterize a mais diversificada possível quanto a períodos de floração, frutificação e porte.

Além disso, o simples fato de uma pessoa, ao sair de sua casa, observar uma árvore florida, ouvir os pássaros cantando, respirar ar puro e sentir prazer em estar naquele lugar, amenizando o estresse da vida urbana agitada, já é gratificante para qualquer ação tomada nesse sentido (BRUN e BRUN, 2006). 
Assim, a Prefeitura Municipal de Porto Alegre ao promulgar uma lei que não leva em conta a fauna urbana, principalmente a avefauna, e sua inter-relação com o verde, compromete a frágil estabilidade sistêmica existente em seu ecossistema urbano.

Falha a lei, por conseguinte, que determina a liberdade para remoções de espécimes arbóreos e ancorando-se em conceitos ortodoxos que definem exóticos e nativos, sem levar em consideração o impacto sobre a fauna existente e potencialmente utilizadora daquele recurso ambiental, seja como fonte alimentar, seja como ambiente de pousio ou mesmo para estabelecimento de área reprodutiva.

\section{REFERÊNCIAS BIBLIOGRÁFICAS}

AGRA-FILHO, Severino S. Conflitos ambientais e os instrumentos da política nacional de meio

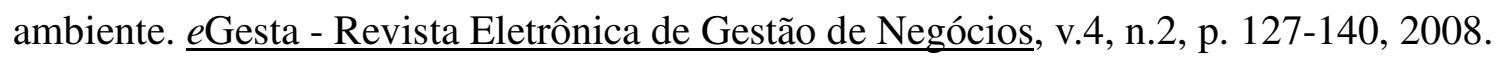

BATTISTI, C.; GIPPOLITI, S. Conservation in the urban-countryside interface: a cautionary note from Italy. Conservation Biology, v. 18, p. 581-583, 2004.

BRASIL. Constituição da República Federativa do Brasil. Diário da União [da República Federativa do Brasil], Brasília, 5 de outubro de 1988.

BRASIL. Lei $\mathrm{N}^{\circ}$ 6.938, de 31 de agosto de 1981. Dispõe sobre a política nacional do meio ambiente, seus fins e mecanismos de formulação e aplicação, e dá outras providências. Diário Oficial da União [da República Federativa do Brasil], Brasília. 02.09.81.

BRASIL. Lei $\mathrm{N}^{\circ}$ 9.985, de 18 de julho de 2000. Institui o Sistema Nacional de Unidades de Conservação da Natureza e dá outras providências. Diário Oficial da União, Brasília, 19 jul. 2000. Disponível on line em: <http://www.planalto.gov.br/ccivil_03/Leis/L9985.htm>.

BRASIL. Lei $N^{\circ} 12.651$, de 25 de maio de 2012. Dispõe sobre a proteção da vegetação nativa; altera as Leis nos 6.938, de 31 de agosto de 1981, 9.393, de 19 de dezembro de 1996, e 11.428, de 22 de dezembro de 2006; revoga as Leis nos 4.771, de 15 de setembro de 1965, e 7.754, de 14 de abril de 1989, e a Medida Provisória no 2.166-67, de 24 de agosto de 2001; e dá outras providências. Disponível on line em: <http://www.planalto.gov.br/ccivil_03/_ato20112014/2012/lei/112651.htm>.

BRASIL. Resolução CONAMA No $013 / 1987$, de 03 de dezembro de 1987. Estabelece condicionantes de compensação ambiental para grandes obras.

BREUSTE, J. H. Decision making, planning and design for the conservation of indigenous vegetation within urban development. Landscape and Urban Planning, v. 68, p.439-452, 2004.

BRUN, E.J.; BRUN, F. G. K. Arborização Urbana \& Qualidade de vida. Conselho em Revista, v. 3, n. 18 , p. $27,2006$. 
CARVALHO, M. A.; NOGUEIRA, F. Serpentes da área urbana de Cuiabá, Mato Grosso: aspectos ecológicos acidentes ofídicos associados. Cadernos de Saúde Publica, v. 14, n. 4, p. 753-763, 1998.

COHEN, B. Urban growth in developing countries: a review of current trends and a caution regarding existing forecasts. World Development, v. 32, p. 23-51, 2003.

FARIA, Ivan D. Compensação ambiental: os fundamentos e as normas; a gestão e os conflitos. Série Textos para Discussão, $n^{\circ}$ 43. Consultoria Legislativa do Senado Federal - Coordenação de Estudos. 2008. 115p.

FENTON, M.B.; ACHARYA, L.; AUDET, D.; HICKEY, M.B.C.; MERIMAN, C.; OBRIST, M.K.; SYME, D.M.; ADKINS, B. Phyllostomid bats (Chiroptera: Phyllostomidae) as indicators of habitat disruption in the Neotropics. Biotropica, n.24, v.3, p.440-446. 1992.

FIORILLO, Celso A. P. Curso de Direito Ambiental Brasileiro. $5^{\text {a }}$ ed. amp. São Paulo: Saraiva, 2004. 428p.

FORMAN, R. T. T.; GORDON, M. Landscape ecology. New York: John Wiley \& Sons, 1986. 23p.

Disponível on line em $<$ http://www.google.com.br/url?sa=t\&rct=j\&q=\&esrc=s\&source=web\&cd=1\&cad=rja\&uact=8\&ve $\mathrm{d}=0 \mathrm{CCYQFjAA} \&$ url=http $\% 3 \mathrm{~A} \% 2 \mathrm{~F} \% 2 \mathrm{Fwww}$.silvafor.org\%2Fassets\%2Fsilva\%2FPDF\%2FLiteratu re\%2FLandscapeEcologyOver.pdf\&ei=zLyjVfrOI4XEwASVvJeIBQ\&usg=AFQjCNGSXvO_HIpO Mhp1Igoz-byM6MwvFw\&sig2=fNIDBhwCeiJ0UnFMLOPC6w>. Acesso em 12 fev. 2015.

FRANCHIN, A. G.; OLIVEIRA, G. M.; MELO, C.; TOMÉ, C. E. R.; MARÇAL JÚNIOR, O. Avifauna do Campus Umuarama, Universidade Federal de Uberlândia, MG. Revista Brasileira de Zoociências, v.6, n.2, p.219-230. 2004.

INSTITUTO BRASILEIRO DE GEOGRAFIA E ESTATÍSTICA (IBGE). Censo Demográfico. Rio de Janeiro: IBGE, 2000. 173p. Disponível on line em $<\mathrm{http}: / / \mathrm{www}$. google.com.br/url? sa=t\&rct=j\&q=\&esrc=s\&source=web\&cd=1\&ved=0CB4QFjAA\& url=http $\% 3 \mathrm{~A} \% 2 \mathrm{~F} \% 2 \mathrm{Fwww.ibge.gov.br} \% 2 \mathrm{Fhome} \% 2 \mathrm{Festatistica} \% 2 \mathrm{Fpopulaca0} \% 2 \mathrm{Fcenso} 2000 \% 2 \mathrm{~F}$ populacao\%2Fcenso2000_populacao.pdf\&ei=ar6jVYOkMMm2wATj36WIBQ\&usg=AFQjCNHOi nCJGhlCYfsX9Md-2zAjpz3wcA\&sig2=70ZT32vXmP2eXckynDVbCg>. Acesso em 12 fev. 2015. JAPYASSÚ, H. F.; BRESCOVIT, A. Biodiversidade araneológica na cidade de São Paulo: a urbanização afeta a riqueza de espécies? 3p. Disponível on line em <www.ambientebrasil.com.br>. Acesso em: 11 março 2015.

LI, F.; WANG, R. S.; PAULUSSEN, J.; LIU, X. S. Comprehensive concept planning of urban greening based on ecological principles: a case study in Beijing, China. Landscape and Urban Planning, v. 72, p.325-336. 2005.

LIMA, C. A.; MENDONÇA, F. Planejamento urbano-regional e crise ambiental, região metropolitana de Curitiba. São Paulo em Perspectiva, v.15, n.1, p.135-143. 2001. 
KONIJNENDIJK, Cecil C. A decade of urban forestry in Europe. Forest Policy and Economics, v. 5, p. 173-186, 2003.

MARQUES-NETO, R.; VIADANA, A. G. Abordagem biogeográfica sobre a fauna silvestre em áreas antropizadas: O Sistema Atibaia-Jaguari em Americana (SP). Sociedade \& Natureza, v.18, p.5-21. 2006.

MARTI, C. D.; KORPIMAKI, E.; JAKSIC, F. M. Trophic structure of raptor communities: a three continent comparison and synthesis. Current Ornithology, v.10, p.47-137. 1993.

MEDELLÍN, R.A.; EQUIHUA, M.; AMIN, M.A. Bat diversity and abundance as indicators of disturbance in Neotropical Rainforests. Conservation Biology, n.14, v.6, p.1666-1675. 2000.

OLIVEIRA, M. M. A. Arborização e avefauna urbana em cidades do interior paulista. Boletim do Centro de Estudos Ornitológicos (CEO), n. 7, p. 10-14, 1990.

PORTO ALEGRE. Decreto No 8.186, de 07 de março de 1983. Regulamenta a Lei Complementar $n^{\circ} 65$ de 22/12/81, no que concerne à proteção da Flora e Fauna e dá outras providências.

PORTO ALEGRE. Decreto N 10.380, de 08 de setembro de 1992. Dispõe sobre critérios de análise de projetos de parcelamento de solo, público ou privado, e de edificações com impacto sobre a vegetação pré-existente.

PORTO ALEGRE. Decreto N 11.476, de 11 de abril de 1996. Dispõe sobre critérios de análise de projetos de parcelamento de solo, público ou privado, e edificações com impacto sobre a vegetação preexistente.

PORTO ALEGRE. Decreto $\mathrm{N}^{\mathrm{0}} 14.353$, de 19 de novembro de 2003. Dispõe sobre a forma de compensação do impacto gerado na supressão autorizada de espécimes vegetais e dá outras providências.

PORTO ALEGRE. Decreto No 15.418, de 20 de dezembro de 2006. Dispõe sobre os procedimentos de supressão, transplante ou podas de espécimes vegetais e dá outras providências.

PORTO ALEGRE. Decreto N ${ }^{\circ} 17.232$, de 26 de agosto de 2011. Dispõe sobre os procedimentos de supressão, transplante ou podas de espécimes vegetais; altera o $\S 1^{\circ}$ do art. $2^{\circ}$ do Decreto $\mathrm{N}^{\circ} 8.186$, de 7 de março de 1983; e revoga os Decretos: $N^{\circ} 10.237$, de 11 de março de 1992; $N^{\circ} 10.258$, de 3 de abril de 1999; e No 15.418 de 20 de dezembro de 2006.

PORTO ALEGRE. Lei Complementar $N^{\circ} 757$, de 14 de janeiro de 2015. Estabelece regras para a supressão, o transplante ou a poda de espécimes vegetais no Município de Porto Alegre, revoga os Decretos $\mathrm{n}^{\text {os }} 10.237$, de 11 de março de 1992, 10.258, de 3 de abril de 1992, 15.418, de 20 de dezembro de 2006, 17.232, de 26 de agosto de 2011, 18.083, de 21 de novembro de 2012, e 18.305, de 28 de maio de 2013, e dá outras providências.

PORTO ALEGRE. Secretaria Municipal do Meio Ambiente. Instrução No 01, de 24 de janeiro de 2008. Dispõe sobre as autorizações referente à compensação, remoção, transplante e poda vegetal. 
PUENTE, André D.; TORRES, Vladimir S.; BLEICKER, Paola P. Floresta urbana e biodiversidade. In: IX CONGRESSO BRASILEIRO DE ARBORIZAÇÃO URBANA, Anais do... Belo Horizonte, 2005. Disponível on line em <http://lproweb.procempa.com.br/pmpa/prefpoa/smam/usu_doc/ floresta_urbana_e_biodiversidade.pdf $>$. Acesso em 11 mar. 2015.

REBELE, F. Urban ecology and special features of urban ecosystems. Global Ecology and Biogeography Letters, v. 4, p. 173-187, 1994.

SCHNEIDER, P. R. Manejo Florestal: Planejamento da Produção Florestal. Santa Maria: CEPEF/FATEC/UFSM. 2002. 492p.

TORRES, Vladimir S. Compensação vegetal: A situação na legislação municipal de Porto Alegre, RS, Brasil. In: XVIII Congresso Brasileiro de Arborização Urbana, 2014, Rio de Janeiro. Anais do .... São Paulo: SBAU, 2014. p. 01-11.

TORRES, Vladimir S.; FARIAS, Mariana F.; TODESCHINI, Felipe. Avaliação Ambiental do Parque Urbano Chico Mendes, Porto Alegre - RS, Brasil. Ciência e Natura, v.37, n.2, p.200-211. 2015

TORRES, Vladimir S.; TODESCHINI, Felipe; FARIAS, Mariana F. Avaliação ecológica de duas áreas urbanas com forte influência antrópica. Revista SBAU, prelo. 2015

TREPL, L. Towards a theory of urban biocoenoses. In: SUKOPP, H.; NUMATA, M.; HUBER, A. (eds.). Urban Ecology as the basis for Urban Planning. Pp. 3-21. The Hague: SPB Academic Publishing. 1995.

TYRVÄINEN, L. The amenity value of the urban forest: an application of the hedonic pricing method. Landscape and Urban Planning, v. 37, p. 211-222, 1997.

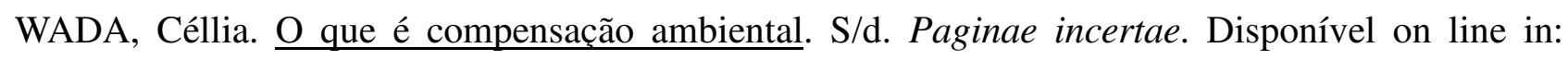
$<$ http://www.lfg.com.br/artigos/Blog/compensacao_ambiental.pdf>. Acesso em 16 fev. 2015.

WHITED, D.; GALATOWITSCH, S.; TESTER, J. R.; SCHIK, K.; LEHTINEN, R.; HUSVETH, J. The importance of local and regional factors in predicting effective conservation planning strategies for wetland bird communities in agricultural and urban landscapes. Landscape and Urban Planning, v. 49, p. 49-65, 2000.

YLI-PELKONEN, V.; NIEMELÄ, J. Linking ecological and social systems in cities: urban planning in Finland as a case. Biodiversity and Conservation, v. 14, p. 1947-1967, 2005.

ZIPPERER, W. C.; WU, J. G.; POUYAT, R. V.; PICKETT, S. T. A. The application of ecological principles to urban and urbanizing landscapes. Ecological Applications, v. 10, p. 685-688, 2000. 


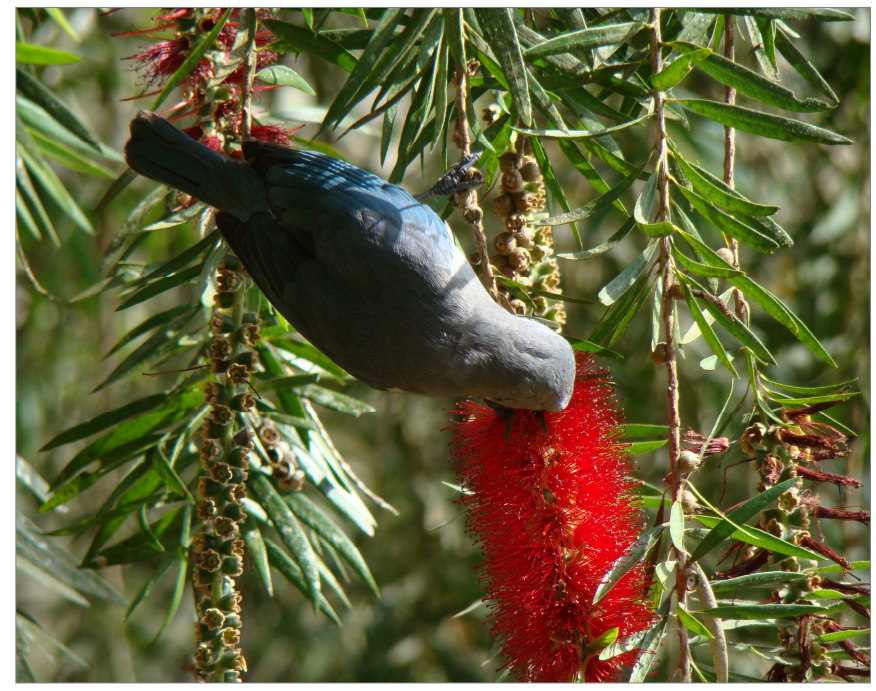

Figura 1.

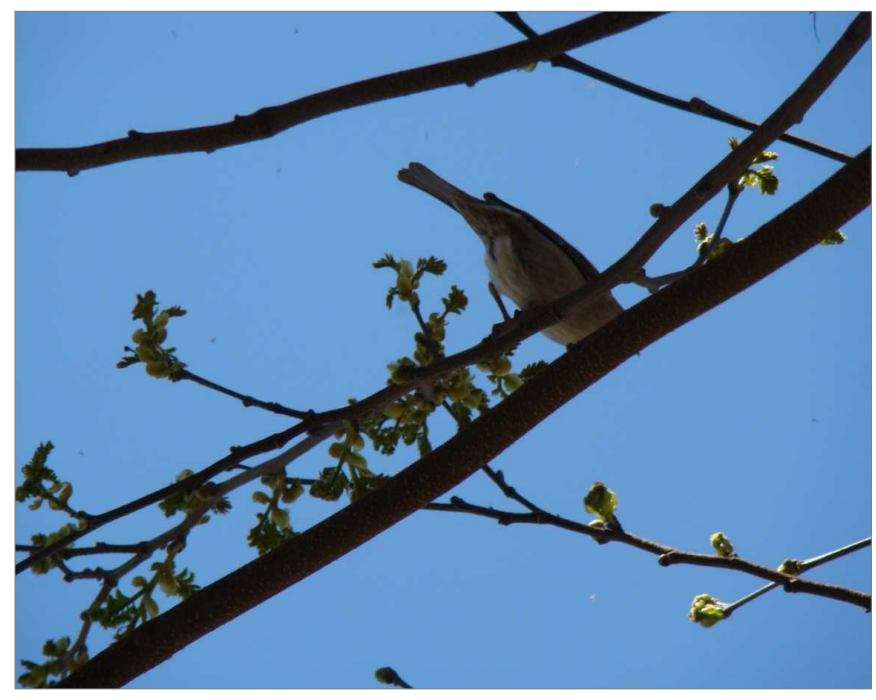

Figura 2. 


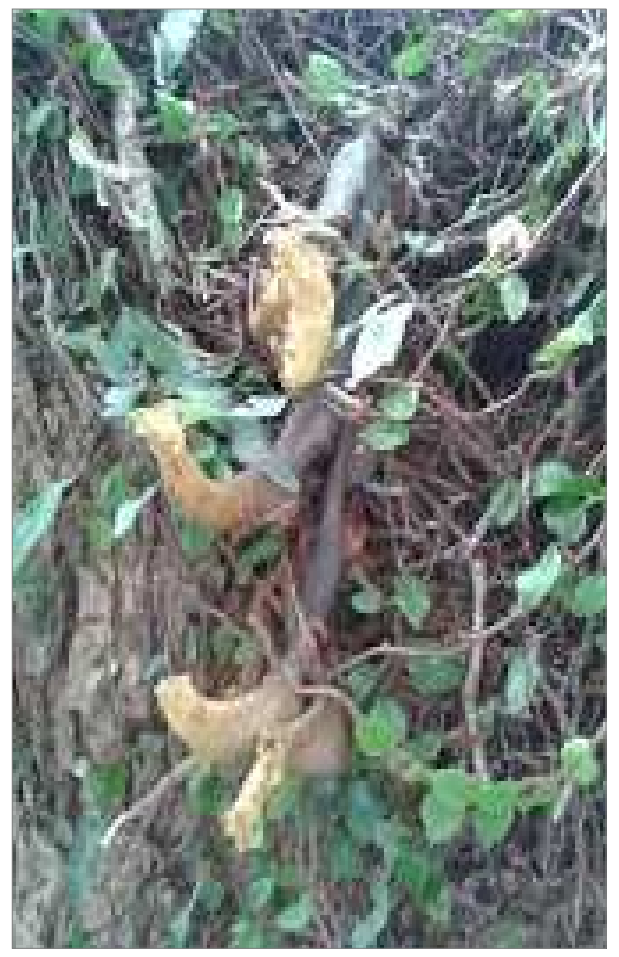

Figura 3. 